Yongjie Li, Chunhong Zheng* and Shouzhi Pu

\title{
Crystal structure and photochromic properties of a novel photochromic perfluordiarylethene containing a triazole bridged pyridine group moiety, $\mathrm{C}_{24} \mathrm{H}_{18} \mathrm{~F}_{6} \mathrm{~N}_{4} \mathrm{~S}_{2}$
}

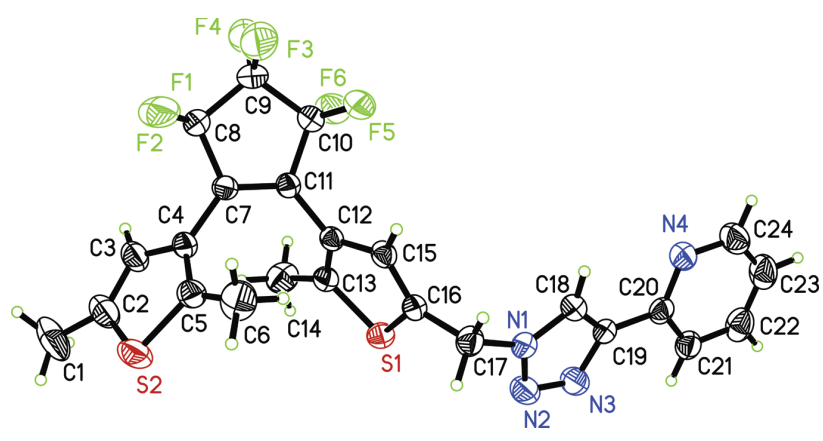

https://doi.org/10.1515/ncrs-2019-0159

Received March 3, 2019; accepted April 23, 2019; available

online June 21, 2019

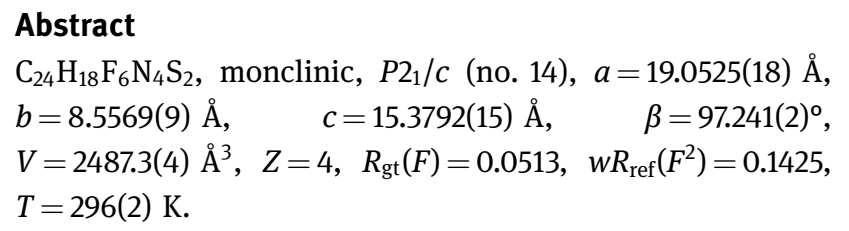

CCDC no.: 1911676

The molecular crystal structure is shown in the figure. Table 1 contains crystallographic data and Table 2 contains the list of the atoms including atomic coordinates and displacement parameters.

\section{Source of material}

The title compound was synthesized by condension reaction of a diarylethene derivative and 2-ethynylpyridine in $45 \%$ yield. Diarylethene derivative $(0.1 \mathrm{~g}, 0.23 \mathrm{mmol})$ was dissolved in $20 \mathrm{~mL}$ solution THF : $\mathrm{H}_{2} \mathrm{O}(\mathrm{v}: \mathrm{v}=4: 1)$, 2ethynylpyridine $(0.024 \mathrm{~g}, 0.23 \mathrm{mmol})$ was added. Then add the catalyst, stir for $1 \mathrm{~h}$ in an ice bath, then stir at room temperature for $6 \mathrm{~h}$. And no more educt was detected by TLC silica gel plate. After the solvent was removed by vacuum evaporation, a yellow solid was obtained with $45 \%$ yield.

*Corresponding author: Chunhong Zheng, Jiangxi Key Laboratory of Organic Chemistry, Jiangxi Science and Technology Normal University, Nanchang 330013, People's Republic of China, e-mail: ezirobot@163.com

Yongjie Li and Shouzhi Pu: Jiangxi Key Laboratory of Organic Chemistry, Jiangxi Science and Technology Normal University, Nanchang 330013, People's Republic of China

○ Open Access. ( 2019 Yongjie Li et al., published by De Gruyter. ((c) BY License.
Table 1: Data collection and handling.

\begin{tabular}{ll}
\hline Crystal: & Colorless, block \\
Size: & $0.28 \times 0.22 \times 0.16 \mathrm{~mm}$ \\
Wavelength: & Mo $K \alpha$ radiation $(0.71073 \AA$ A $)$ \\
$\mu:$ & $0.28 \mathrm{~mm}^{-1}$ \\
Diffractometer, scan mode: & Bruker SMART, $\varphi$ and $\omega$-scans \\
$\theta_{\text {max }}$, completeness: & $27.7^{\circ},>97 \%$ (up to $\left.25.3,>99 \%\right)$ \\
$N(h k l)_{\text {measured }}, N(h k l)_{\text {unique }}, R_{\text {int }}:$ & $14666,5652,0.052$ \\
Criterion for $I_{\text {obs }}, N(h k l)_{\text {gt }}:$ & $I_{\text {obs }}>2 \sigma\left(I_{\text {obs }}\right), 2432$ \\
$N(\text { param })_{\text {refined }}:$ & 373 \\
Programs: & Bruker programs [1], SHELX [2, 3] \\
\hline
\end{tabular}

M.p. $451 \mathrm{~K}-453 \mathrm{~K}$. The title compound crystallized from hexane-dichloromethane cosolvent at room temperature and produced the suitable colorless crystal.

\section{Experimental details}

The hydrogen atoms were located by geometrically calculations, and their positions and thermal parameters were fixed during the structure refinement. The occupancies of the disorder fluorine atoms at the central cyclopentene ring are refined. All $\mathrm{H}$ atoms attached to $\mathrm{C}$ were fixed geometrically and treated as riding with $\mathrm{C}-\mathrm{CH}=0.96 \AA$ (methyl) or $0.93 \AA$ (ethyl and thienyl) with $U_{\text {iso }}(\mathrm{H})=1.2 U_{\text {eq }}$ (ethyl and thienyl) or $U_{\text {iso }}(\mathrm{H})=1.5 U_{\text {eq }}$ (methyl).

\section{Discussion}

Among the organic photochromic compounds, diarylethene derivatives have attracted remarkable research interests due to their wide applications in optical memory media and photo-optical switching devices [4-6]. In recent years, various diarylethene chemosensors have been developed to identify various chemical species, such as metal ions, anions, and amino acids [7, 8]. The sensing mechanism of these diarylethene derivatives can be determined by analytical methods such as nuclearmagnetic resonance, mass spectrometry, and infrared, but few of them are analyzed from their own structural characteristics. Therefore, in order to understand the binding mechanism, the structure of the sensor is necessary to be confirmed by single-crystal X-ray diffraction analysis. Although many photochromic diarylethene compounds have been reported so far, 
Table 2: Fractional atomic coordinates and isotropic or equivalent isotropic displacement parameters $\left(\AA^{2}\right)$.

\begin{tabular}{|c|c|c|c|c|}
\hline Atom & $x$ & $y$ & $z$ & $\boldsymbol{U}_{\text {iso }} * / \boldsymbol{U}_{\mathrm{eq}}$ \\
\hline $\mathrm{F} 1^{\mathrm{a}}$ & $0.122(2)$ & $0.881(2)$ & $0.9431(18)$ & $0.138(8)$ \\
\hline $\mathrm{F}^{\mathrm{a}}$ & $0.0652(8)$ & $0.869(2)$ & $0.8118(17)$ & $0.105(5)$ \\
\hline $\mathrm{F}^{\mathrm{a}}$ & $0.2161(10)$ & $1.051(2)$ & $0.870(2)$ & $0.131(6)$ \\
\hline F4 & $0.14665(11)$ & $1.0525(3)$ & $0.76538(17)$ & $0.1213(9)$ \\
\hline$F 5^{a}$ & $0.2974(13)$ & $0.881(3)$ & $0.790(2)$ & $0.087(6)$ \\
\hline$F 6^{a}$ & $0.2149(9)$ & $0.850(2)$ & $0.6875(12)$ & $0.095(5)$ \\
\hline $\mathrm{F} 1^{\prime \mathrm{a}}$ & $0.1410(19)$ & $0.889(2)$ & $0.9535(14)$ & $0.144(7)$ \\
\hline$F 2^{\prime a}$ & $0.0671(10)$ & $0.8676(18)$ & $0.843(3)$ & $0.134(8)$ \\
\hline$F 3^{\prime a}$ & $0.2215(6)$ & $1.040(2)$ & $0.8928(18)$ & $0.106(5)$ \\
\hline $\mathrm{F} 5^{\prime \mathrm{a}}$ & $0.3003(15)$ & $0.886(4)$ & $0.814(3)$ & $0.100(6)$ \\
\hline$F 6^{a}$ & $0.2220(10)$ & $0.870(2)$ & $0.6941(11)$ & $0.105(5)$ \\
\hline N1 & $0.45454(12)$ & $0.2803(3)$ & $0.72093(16)$ & $0.0626(7)$ \\
\hline N2 & $0.43846(15)$ & $0.1486(3)$ & $0.6751(2)$ & $0.0863(9)$ \\
\hline N3 & $0.47471(15)$ & $0.1516(3)$ & $0.60742(19)$ & $0.0827(8)$ \\
\hline N4 & $0.58665(12)$ & $0.4671(3)$ & $0.54917(17)$ & $0.0713(7)$ \\
\hline S1 & $0.28102(4)$ & $0.28684(9)$ & $0.71636(5)$ & $0.0659(3)$ \\
\hline S2 & $0.10461(6)$ & $0.30905(11)$ & $0.97695(6)$ & $0.0964(4)$ \\
\hline $\mathrm{C} 1$ & $-0.0385(2)$ & $0.3078(5)$ & $0.9069(3)$ & $0.1278(17)$ \\
\hline $\mathrm{H} 1 \mathrm{~A}$ & -0.034798 & 0.216889 & 0.943729 & 0.192 * \\
\hline H1B & -0.072353 & 0.378864 & 0.926100 & $0.192^{*}$ \\
\hline $\mathrm{H} 1 \mathrm{C}$ & -0.053622 & 0.277287 & 0.847376 & $0.192^{*}$ \\
\hline $\mathrm{C} 2$ & $0.03233(18)$ & $0.3866(4)$ & $0.9121(2)$ & $0.0792(10)$ \\
\hline C3 & $0.05223(17)$ & $0.5156(4)$ & $0.8724(2)$ & $0.0709(9)$ \\
\hline H3SA & 0.020912 & 0.575774 & 0.835041 & $0.085^{*}$ \\
\hline $\mathrm{C} 4$ & $0.12584(15)$ & $0.5533(3)$ & $0.89234(18)$ & $0.0541(7)$ \\
\hline C5 & $0.16155(17)$ & $0.4518(4)$ & 0.94930(19) & $0.0646(8)$ \\
\hline $\mathrm{C} 6$ & $0.23656(18)$ & $0.4527(5)$ & $0.9881(2)$ & $0.0997(12)$ \\
\hline $\mathrm{H} 6 \mathrm{~A}$ & 0.263116 & 0.383301 & 0.955636 & 0.150 * \\
\hline H6B & 0.240115 & 0.418834 & 1.047965 & $0.150^{*}$ \\
\hline $\mathrm{H} 6 \mathrm{C}$ & 0.255171 & 0.556713 & 0.985794 & $0.150^{*}$ \\
\hline $\mathrm{C} 7$ & $0.15880(14)$ & $0.6873(3)$ & $0.85387(17)$ & $0.0517(7)$ \\
\hline $\mathrm{C} 8$ & $0.1325(2)$ & $0.8487(4)$ & $0.8648(3)$ & $0.0759(11)$ \\
\hline C9 & $0.18205(19)$ & $0.9565(4)$ & $0.8228(3)$ & $0.0746(10)$ \\
\hline C10 & $0.23103(18)$ & $0.8471(3)$ & $0.7793(2)$ & $0.0637(8)$ \\
\hline C11 & $0.21366(14)$ & $0.6858(3)$ & $0.80750(17)$ & $0.0494(7)$ \\
\hline C12 & $0.25258(13)$ & $0.5486(3)$ & $0.78073(16)$ & $0.0451(6)$ \\
\hline C13 & $0.22139(14)$ & $0.4319(3)$ & $0.73069(18)$ & $0.0525(7)$ \\
\hline C14 & $0.14653(16)$ & $0.4188(4)$ & $0.6881(2)$ & $0.0821(10)$ \\
\hline $\mathrm{H} 14 \mathrm{~A}$ & 0.122517 & 0.516171 & 0.693949 & $0.123^{*}$ \\
\hline H14B & 0.122909 & 0.337243 & 0.715903 & $0.123^{*}$ \\
\hline $\mathrm{H} 14 \mathrm{C}$ & 0.146151 & 0.394734 & 0.627058 & $0.123^{*}$ \\
\hline C15 & $0.32546(14)$ & $0.5210(3)$ & $0.80656(17)$ & $0.0533(7)$ \\
\hline H15A & 0.354723 & 0.591713 & 0.839714 & $0.064^{*}$ \\
\hline C16 & $0.34867(14)$ & $0.3831(3)$ & $0.77876(17)$ & $0.0530(7)$ \\
\hline C17 & $0.42050(15)$ & $0.3130(4)$ & $0.7994(2)$ & $0.0685(9)$ \\
\hline $\mathrm{H} 17 \mathrm{~A}$ & 0.450181 & 0.383935 & 0.837082 & $0.082^{*}$ \\
\hline H17B & 0.416672 & 0.216390 & 0.831533 & $0.082^{*}$ \\
\hline C18 & $0.49961(14)$ & $0.3666(4)$ & $0.6817(2)$ & $0.0648(8)$ \\
\hline H18 & 0.518537 & 0.463015 & 0.699980 & $0.078^{*}$ \\
\hline C19 & $0.51219(14)$ & $0.2852(3)$ & $0.60984(19)$ & $0.0564(7)$ \\
\hline $\mathrm{C} 20$ & $0.55885(14)$ & $0.3229(4)$ & $0.54358(19)$ & $0.0575(8)$ \\
\hline C21 & $0.57266(16)$ & $0.2141(4)$ & $0.4813(2)$ & $0.0692(9)$ \\
\hline
\end{tabular}

Table 2 (continued)

\begin{tabular}{lrrrr}
\hline Atom & $\boldsymbol{x}$ & $\boldsymbol{y}$ & $\boldsymbol{z}$ & $\boldsymbol{U}_{\text {iso }} \boldsymbol{U}_{\text {eq }}$ \\
\hline $\mathrm{H} 21 \mathrm{~A}$ & 0.551516 & 0.116015 & 0.479184 & $0.083^{*}$ \\
$\mathrm{C} 22$ & $0.61857(19)$ & $0.2548(5)$ & $0.4223(2)$ & $0.0850(10)$ \\
$\mathrm{H} 22 \mathrm{~A}$ & 0.629064 & 0.184065 & 0.379879 & $0.102^{*}$ \\
$\mathrm{C} 23$ & $0.64814(18)$ & $0.3992(5)$ & $0.4272(2)$ & $0.0914(12)$ \\
$\mathrm{H} 23 \mathrm{~A}$ & 0.679658 & 0.428616 & 0.388644 & $0.110^{*}$ \\
$\mathrm{C} 24$ & $0.63076(18)$ & $0.5008(5)$ & $0.4899(3)$ & $0.0875(11)$ \\
$\mathrm{H} 24$ & 0.650801 & 0.600071 & 0.491588 & $0.105^{*}$ \\
\hline
\end{tabular}

accupancy: 0.5 .

very few diarylethene derivatives having an ion-recognizing group have been reported, which undergo the photocyclization reaction in the crystalline phase. The single-crystalline photochromic reactivity depended on both anti-parallel mode and the distance between active carbon atoms which is less than $4.2 \AA[9,10]$.

To date, novel diarylethene derivatives with a triazole bridged group base moiety have attracted much attention because their photochromic reactivity could be effectively modulated by light, and metal ions [11]. It is well known that these diarylethenes having a symmetric thienyl group have excellent thermal stabilities [12]. Our group has reported a lot of diarylethene compounds with excellent optical properties and analysized their crystal structures to further guide the functional molecular design [13-15]. In addition, the introduction of fluorophores with ions recognition on the diarylethene of the symmetric thienyl group has attracted a great deal of interest among researchers. In this work, a diarylethene derived triazole bridged derivative has been synthesized through condensation reaction [16, 17]. A novel crystal 1-(2,5-dimethyl-3-thienyl)-2-\{2-methyl-5-[(2pyridyl)-triazole-methyl]-3-thienyl\}-perfluorocyclopentene was obtained.

The molecule adopts an antiparallel conformation, and the distance between the photoactive carbon atoms (C5 ... C13) was 3.684 A. Based on the empirical rule, the crystal displayed a notable color change upon irradiation with UV light. The colorless crystal turned purple upon irradiation with $313 \mathrm{~nm}$ light, and the colored crystals reverted to a colorless state upon irradiation with visible light. The photochromism was highly consistent in crystalline phase even after 100 repeat cycles, indicating that it is favorable for applications in a certain optoelectronic device [18]. In the perfluorocyclopentene ring, the both thiophene rings are linked by the $\mathrm{C} 7=\mathrm{C} 11$ double bond 1.339 (7) $\AA$, which is shorter than the formal single bond (such as C4-C7, 1.469(7) A and C7C8, 1.485(8) A. The molecule includes four kinds of planar rings and they can form three dihedral angles between every two adjacent planar rings. The dihedral angles between the 
perfluorocyclopentene ring and the two adjacent thiophene rings were $58.5^{\circ}$ for $\mathrm{S} 2 / \mathrm{C} 7-\mathrm{C} 11$ and $61.2^{\circ}$ for S1/C12,13-C15,16, and that between the triazole ring and pyridine ring was $8.6^{\circ}$.

The title compound is packed with antiparallel and crisscross neighbouring molecules each other. Intermolecular hydrogen bonds connect molecules of the title compound with each other. These molecular interactions together with hydrogen bonding may strengthen the stability of the framework structure.

The absorption spectrum of open-form the title compound exhibited an intense band centered at $248 \mathrm{~nm}$ in acetonitrile. Irradiation with UV light $(297 \mathrm{~nm})$ resulted in the emergence of a new absorption band at $555 \mathrm{~nm}$ with a color change from colorless to purple due to the formation of the closed-ring isomer. The purple color faded to colorless upon irradiation with visible light ( $>510 \mathrm{~nm}$ ), and the absorption spectrum returned to the initial state. After 100 repeat cycles, the diarylethenes still showed good photochromism with only $13 \%$ degradation for its closed-ring isomer.

Acknowledgements: This work was supported by the Project of Jiangxi Education Office (GJJ180621). We thank the editor for providing the figure.

\section{References}

1. Bruker: APEX3, SAINT-Plus, XPREP. Bruker AXS Inc., Madison, WI, USA (2016).

2. Sheldrick, G. M.: SHELXT - Integrated space-group and crystalstructure determination. Acta Crystallogr. A71 (2015) 3-8.

3. Sheldrick, G. M.: Crystal structure refinement with SHELXL. Acta Crystallogr. C71 (2015) 3-8.

4. Xu, H. Y.; Wang, R. J.; Fan, C. B.; Liu, G.; Pu, S. Z.: Synthesis and photochromism of new asymmetrical diarylethenes with a variable heteroaryl ring and a quinoline unit. Turk. J. Chem. 40 (2016) 38-53.

5. Irie, M.: Phororeactive Materials for Ultrahigh-density Optical Memory, Elsevier, Amsterdam (1993).

6. Irie, M.; Fukaminato, T.; Matsuda, K.; Kobatake, S.: Photochromism of diarylethene molecules and crystals: Memories, switches, and actuators. Chem. Rev. 114 (2014) 12174-12277.
7. Pu, S. Z.; Sun, Q.; Fan, C. B.; Wang, R. J.; Liu, G.: Recent advances in diarylethene-based multi-responsive molecular switches. J. Mater. Chem. C 4 (2016) 3075-3093.

8. Li, S. Y.; Zhang, D. B.; Wang, J. Y.; Lu, R. M.; Zheng, C. H.; Pu, S. Z.: A novel diarylethene-hydrazinopyridine-based probe for fluorescent detection of aluminum ion and naked-eye detection of hydroxide ion. Sens. Actuators B Chem. 245 (2017) 263-272.

9. Ramamurthy, V.; Venkatesan, K.: Photochemical reactions of organic crystals. Chem. Rev. 87 (1987) 433-481.

10. Kobatake, S.; Uchida, K.; Tsuchida, E.; Irie, M.: Singlecrystalline photochromism of diarylethenes: reactivitystructure relationship. Chem. Commun. (2002) 23 2804-2805.

11. Jin, J. Y.; Zhang, J. J.; Zou, L.; Tian, H.: Near-infrared photochromic behavior in a donor-acceptor type diarylethene modulated by the cyanide anion. Analyst. 138 (2013) 1641-1644.

12. Fan, C. B.; Liu, Z. Q.; Gong, L. L.; Zheng, A. M.; Zhang, L.; Yan, C. S.; Wu, H. Q.; Feng, X. F.; Luo, F.: Photoswitching adsorption selectivity in a diarylethene-azobenzene MOF. Chem. Commun. 53 (2017) 763-766.

13. Fan, C. B.; Liu, Y.; Zhang, D. B.; Pu, S. Z.: Crystal structure and crystalline state multiphotochromism properties of a fused diarylethene dimer. Chinese J. Struct. Chem. 38 (2019) 251-256.

14. Lv, J. F.; Li, H.; Pu, S. Z.: Structure and photochromism of 1,2-bis[2-methyl-5-(3-quinolyl)-3-thienyl]-3,3,4,4,5,5hexafluorocyclopent-1-ene, $\mathrm{C}_{33} \mathrm{H}_{20} \mathrm{~F}_{6} \mathrm{~N}_{2} \mathrm{~S}_{2}$, Z. Kristallogr. NCS 233 (2018) 999-1002.

15. Huang, X. Q.; Zheng, C. H.; Pu, S. Z.: Crystal structure and photochromism of 1-(2-ethyl-5-formylthiophen-3yl)-2-(2-cyano1,5-dimethyl-4-pyrrl)-3,3,4,4,5,5-hexafluorocyclopent-1-ene, $\mathrm{C}_{19} \mathrm{H}_{14} \mathrm{~F}_{6} \mathrm{~N}_{2}$ OS. Z. Kristallogr. NCS 234 (2019) 181-183.

16. Ma, L.; Liu, G.; Pu, S. Z.; Ding, H. C.; Li, G.: A highly selective fluorescent chemosensor for copper ion based on a new diarylethene with triazole-linked fluorescein. Tetrahedron. 71 (2016) 985-991.

17. Duan, F.; Liu, G.; Fan, C. B.; Pu, S. Z.: Synthesis and photochromism of a novel amphiphilic diarylethene bearing two cholic acid groups. Tetrahedron Lett. 57 (2016) 1963-1966.

18. Cheng, H. B.; Zhang, H. Y.; Liu, Y.: Dual-stimulus luminescent lanthanide molecular switch based on an unsymmetrical diarylperfluorocyclopentene. J. Am. Chem. Soc. 135 (2013) 10190-10193. 